\title{
Основные проблемы корпоративной социальной ответственности бизнеса и пути их решения
}

\author{
Мария Михайловна БАСОВА, \\ к.э.н., доцент Департамента учета, анализа и аудита \\ ФГОБУ ВО «Финансовый университет при Правительстве Российской Федерации» \\ (Финансовый университет), Россия, Москва \\ E-mail: mashashik@mail.ru
}

Basova Maria Mikhailovna, candidate of science in economics

Associate Professor, Department of accounting, analysis and audit Financial University under the Government of the Russian Federation

\begin{abstract}
Аннотация: В статье приводятся основные направления концепции корпоративной социальной ответственности бизнеса (КСОБ), проводится анализ ее реализации на внешнем и внутреннем уровнях в разрезе экономических, социальных и экологических аспектов на примере нефинансовой отчетности публичного акционерного общества «Новолипецкий металлургический комбинат (ПАО «НЛМК»). Доказывается, что с целью реализации основных направлений концепции КСОБ, внесения необходимых изменений в свою деятельность, улучшения качества управления производством и социальным развитием, а также эффективным управлением нефинансовыми рисками на первый план выдвигается проблема усовершенствования нефинансового отчета путем включения в него проработанного экономикоматематического инструментария по выбору и взаимодействию компании с заинтересованными сторонами. В работе приведен пример ранжирования стейкхолдеров ПАО «НЛМК» на основе использования моделей Брайсона и Митчелла, Агла и Вуда.
\end{abstract}

Ключевые слова: Корпоративная социальная ответственность бизнеса, нефинансовые риски, заинтересованные стороны, стейкхолдеры, социальные инвестиции, нефинансовая отчетность по устойчивому развитию компании, модель Брайсона, модедь Митчелла, Агла и Вуда.

\section{THE MAIN PROBLEMS OF CORPORATE SOCIAL RESPONSIBILITY AND WAYS OF THEIR SOLUTION}

Abstract: the article presents the main directions of the concept of corporate social responsibility (CSOB), the analysis of its implementation at external and internal levels in the context of economic, social and environmental issues on the example of non-financial reporting of «Novolipetsk Steel» (NLMK). It is proved that the purpose of the implementation of the main directions of the concept CSOB, making the necessary changes in their activities, improve the quality of production management and social development, and the effective management of nonfinancial risks, there is the problem of improving non-financial report by including elaborate mathematical tools for the selection and interaction of company with interested parties. The paper presents an example of the ranking of stakeholders of "NLMK" usage-based models of Bryson and Mitchell, Agle, Wood.

Key words: Corporate social responsibility, non-financial risks, stakeholders, stakeholders, social investments, sustainability reporting on sustainable development of the company, the model of Bryson, model Mitchell, Agle, Wood.

В России корпоративную социальную ответственность бизнеса (КСОБ) условно следует рассматривать на внешнем и внутреннем уровнях в разрезе экономических, социальных и экологических аспектов.

Сбалансированное сочетание социальных, экологических и экономических составляющих, несомненно, приведет к улучшению репутации организаций, повышению эффективности персонала и лояльности потребителей, снижению предпринимательских рисков, укреплению конкурентоспособности и т.д. Важную 
роль в определении и практической реализации системы устойчивого развития играет нефинансовая (интегрированная, корпоративная, социальная) отчетность[2].

Проанализируем отчет ОАО «Новолипецкий металлургический комбинат (ПАО «НЛМК») на предмет полноты и глубины отражения в ней концепции КСОБ. Для справки. В 2015 году численность персонала Группы НЛМК составила 56,7 тыс. чел., производительность труда по Липецкой площадке выросла по сравнению с 2014 годом на 6\%, выручка составила \$8 млрд, показатель EBITDA \$1,9 млрд, чистая прибыль \$1 млрд.

В социальном плане в отчетности предприятия достаточно полно представлены внутренние аспекты КСОБ, а именно рассматриваются вопросы, касающиеся проблем оплаты труда и стимулирования персонала, обеспечения потребностей в специалистах, системы обучения работников и работы с кадровым резервом, повышения профессионального уровня и квалификации персонала, охраны труда и промышленной безопасности, эффективного продвижения культуры безопасного производства, социальные программы по охране здоровья, культурной и спортивно-оздоровительной деятельности, жилищные программы и др.

Приведем некоторые цифры из отчета за 2015 год. Количество несчастных случаев на производстве снизилось на $29 \%$, более $50 \%$ сотрудников ежегодно участвуют в образовательных инициативах. Коэффрициент частоты травм с потерей трудоспособности (LTIFR) на российских активах Группы НЛМК составил 0,43 и снизился на 22\% по сравнению с 2014 годом.

Достаточно полно в отчетности предприятия представлена и внешняя социальная составляющая. Общая сумма инвестиций в социальное развитие регионов присутствия за 2015 г. по российским компаниям Группы НЛМК составила 3,3 млрд рублей (\$54 млн). Структура социальных инвестиций приведена в табл. 1.

Таблица 1. Структура социальных инвестиций Группы НЛМК в социальное развитие регионов присутствия в 2015 г.

\begin{tabular}{|l|l|}
\hline Спорт & $12 \%$ \\
\hline Здравоохранение & $43 \%$ \\
\hline Культура & $5 \%$ \\
\hline Благотворительность & $20 \%$ \\
\hline Работа с детьми и молодежью & $6 \%$ \\
\hline Образование & $14 \%$ \\
\hline
\end{tabular}

В экологической составляющей в нефинансовом отчете внутренний аспект КСОБ представлен данными о внедрении безотходных технологий производства; снижении удельных выбросов в атмосферу; соблюдении законодательных норм в области охраны окружающей среды; сокращении удельного использования водных ресурсов (по этому показателю в компании уже превышены лучшие мировые стандарты); о затратах на охрану окружающей среды и платежах предприятия за негативное воздействие на окружающую среду. Немного цифр. В 2015 г. инвестиции в природоохранные проекты предприятий Группы НЛМК превысили $\$ 100$ млн., кумулятивные инвестиции на экологические программы с 2001 г. составили \$1,3 млрд, снижение удельных затрат энергии составило 1\%, удельные выбросы в атмосферу сокращены по сравнению с 2014 годом до 20,9 кг/т. Поскольку все внутренние проекты нацелены в конечном итоге на «экологизацию» территорий присутствия, то в качестве внешних аспектов стоит обратить внимание на общественную оценку природоохранной деятельности компании. Как пример - победа Группы НЛМК в номинации «Экология города» Всероссийского конкурса «Национальная экологическая премия им. В. И. Вернадского» за реализацию природоохранного проекта «Технология безводного охлаждения доменного шлака». В 2015 г. Группа НЛМК получила серебряную медаль международной промышленной выставки «Металл-Экспо-2015» за реализацию на Липецкой площадке проекта «Технология безводного охлаждения доменного шлака», позволяющего снизить эмиссию сероводорода в 8 раз. Реализация экологических проектов позволила компании добиться значительного снижения воздействия производства на экологию. Данных об участии компании в проектах, направленных на решение экологических проблем, в отчетности нет.

В экономическом аспекте достаточно полно рассмотрены вопросы корпоративного развития организации уплаты налогов, укрепления деловой репутации и формирование имиджа организации. 
Процесс развития компании - это постоянный процесс взаимодействия, согласования и разрешения противоречий в ожиданиях и требованиях стейкхолдеров и самой компании как самоорганизующейся структуры. Основной целью компании по-прежнему является рост ценности для акционеров. Однако в процессе своего функционирования компания создает ценность для всех ее участников, и именно это позволяет ей развиваться, повышать свою устойчивость [3].

Дальнейший анализ нефинансовой отчетности устойчивого развития ПАО «НЛМК» показал, что в области корпоративной социальной ответственности бизнеса очень схематично представлены проблемы управления нефинансовыми рисками, которые исходят от стейкхолдеров.

Что такое нефинансовый риск? Нефинансовый риск можно определить как возможность недостижения определенных целей компании, связанных с сознательными или несознательными противодействиями заинтересованных сторон. Управлять этими рисками, на наш взгляд, можно только путем эффективного выстраивания диалоговых фрорм взаимодействия со всеми заинтересованными сторонами организации.

Что же мы имеем в отчетности? В нефинансовом отчете ПАО «НЛМК» имеется раздел «Диалог с заинтересованными сторонами», в котором декларируется утверждение, что КСОБ НЛМК рассматривает как постоянную деятельность, которая включает группу вопросов, связанных с выбором и применением методов оптимального взаимодействия с ключевыми стейкхолдерами для принятия взаимовыгодных решений.

Приводятся и некоторые данные об активном диалоге с заинтересованными сторонами: было проведено свыше 370 встреч с акционерами и инвесторами. Не вполне аргументировано утверждается, что при определении ключевых стейкхолдеров компания учитывала степень их влияния на деятельность Группы НЛМК, а далее приводится стандартный перечень ключевых стейкхолдеров, а также типовая таблица, включающая область интересов заинтересованных сторон, инструменты двустороннего их диалога и обратная связь.

Вместе с тем, вопросы взаимодействия со всеми заинтересованными сторонами через постоянную систему анализа и поиска взаимовыгодных решений как одного из методов управления нефинансовыми рисками в отчете не приводятся. С этой целью, на наш взгляд, отчет должен быть дополнен методами оптимального взаимодействия с ключевыми заинтересованными сторонами: конкретными данными по выявлению и мониторингу рисковых ситуаций, ранжированию стейкхолдеров на основе использования экономикоматематических методов, составлению «карты стейкхолдеров», разработке сценарного анализа поведения и взаимодействия компании со всеми заинтересованными сторонами.

В качестве примера в табл. 2 и 4 на основе использования моделей Брайсона и Митчелла, Агла и Вуда представлено ранжирование стейкхолдеров ПАО «НЛМК».

Таблица 2. Ранжирование стейкхолдеров ПАО «НЛМК» на основе использования моделей Митчелла, Агла и Вуда

\begin{tabular}{|c|c|c|c|c|}
\hline $\begin{array}{l}\text { Стейк- } \\
\text { холдер }\end{array}$ & Характеристика интересов & $\begin{array}{l}\text { Легитимность } \\
\text { (интересов } \\
\text { стейкхолдера в } \\
\text { отношении бизнеса) }\end{array}$ & $\begin{array}{l}\text { Власть (способность } \\
\text { стейкхолдера достичь своих } \\
\text { интересов путем принуждения, } \\
\text { финансов и др.) }\end{array}$ & $\begin{array}{l}\text { Срочность (скорость, с } \\
\text { которой должны } \\
\text { удовлетворяться интересы } \\
\text { стейкхолдера) }\end{array}$ \\
\hline $\begin{array}{l}\text { Сотрудники } \\
\text { компании }\end{array}$ & $\begin{array}{l}\text { Заинтересованы в заработной } \\
\text { плате и социальном пакете } \\
\text { (имеют право требовать з/п и } \\
\text { взыскивать ее в судебном } \\
\text { порядке), безопасности труда } \\
\text { (законодательно регулируемая } \\
\text { сфера, работодатель обязан } \\
\text { обеспечивать безопасность } \\
\text { рабочих мест, условий труда и } \\
\text { пр.), карьере }\end{array}$ & $\begin{array}{l}\text { + (защищены с точки } \\
\text { зрения государства) }\end{array}$ & $\begin{array}{l}\text { - (нет полноценных } \\
\text { инструментов принуждения } \\
\text { компании повышать 3/п, } \\
\text { обеспечивать карьерный рост } \\
\text { и пр.) }\end{array}$ & $\begin{array}{l}+ \text { + (урегулирован } \\
\text { законодательством) }\end{array}$ \\
\hline $\begin{array}{l}\text { Профсоюз- } \\
\text { ные } \\
\text { органи- } \\
\text { зации }\end{array}$ & $\begin{array}{l}\text { Заинтересованы в соблюдении } \\
\text { трудового законодательства и } \\
\text { выполнении условий трудового } \\
\text { договора, достойном уровне } \\
\text { заработной платы и социальной } \\
\text { защищенности сотрудников }\end{array}$ & $\begin{array}{l}+ \text { (обеспечивается } \\
\text { коллективным } \\
\text { договором) }\end{array}$ & $\begin{array}{l}\text { - (нет инструментов } \\
\text { принуждения) }\end{array}$ & $\begin{array}{l}\text { - (срочность ответов на } \\
\text { запросы профсоюза за } \\
\text { исключением вопросов, } \\
\text { связанных с коллективным } \\
\text { договором, остается на } \\
\text { усмотрение компании) }\end{array}$ \\
\hline
\end{tabular}


анализ | прогноз | управление электронный научно-экономический журнал

\begin{tabular}{|c|c|c|c|c|}
\hline $\begin{array}{l}\text { Акционеры } \\
\text { и } \\
\text { инвесторы }\end{array}$ & $\begin{array}{l}\text { Дивидендные выплаты, высокие } \\
\text { производственные и финансовые } \\
\text { результаты, соблюдение } \\
\text { стратегии и достижение } \\
\text { стратегических целей компании }\end{array}$ & $\begin{array}{l}\text { + (имеют } \\
\text { имущественные и } \\
\text { управленческие } \\
\text { (акционеры) права) }\end{array}$ & $\begin{array}{l}\text { + (могут использовать } \\
\text { финансовые и управленческие } \\
\text { ресурсы для достижения } \\
\text { интересов) }\end{array}$ & $\begin{array}{l}\text { + (из-за наличия большого } \\
\text { количества властных } \\
\text { полномочий интересы } \\
\text { должны удовлетворяться } \\
\text { срочно) }\end{array}$ \\
\hline $\begin{array}{l}\text { Потреби- } \\
\text { тели }\end{array}$ & $\begin{array}{l}\text { Высокое качество продукции, } \\
\text { доступные цены, выполнение } \\
\text { договорных обязательств, } \\
\text { своевременное рассмотрение } \\
\text { претензий (обеспечено } \\
\text { договорными условиями) }\end{array}$ & $\begin{array}{l}+ \text { (основывается на } \\
\text { договорных условиях) }\end{array}$ & $\begin{array}{l}\text { - (условия взаимодействия } \\
\text { описаны в договоре, } \\
\text { отсутствуют рычаги } \\
\text { принуждения) }\end{array}$ & $\begin{array}{l}\text { + (высокая срочность } \\
\text { обусловлена как } \\
\text { договорными условиями, } \\
\text { так и необходимостью } \\
\text { оперативно удовлетворять } \\
\text { запросы потребителей для } \\
\text { поддержания имиджа } \\
\text { бизнеса) }\end{array}$ \\
\hline $\begin{array}{l}\text { Жители } \\
\text { регионов }\end{array}$ & $\begin{array}{l}\text { Развитие региона, соблюдение } \\
\text { экологических норм и } \\
\text { не нанесение вреда здоровью } \\
\text { региона («грязный» характер } \\
\text { производства НЛМк), } \\
\text { потенциальные рабочие места }\end{array}$ & $\begin{array}{l}\text { + (важная часть } \\
\text { интересов, связанных } \\
\text { с экологией, } \\
\text { подтверждена } \\
\text { законодательно) }\end{array}$ & $\begin{array}{l}\text { - (нет инструментов } \\
\text { принуждения) }\end{array}$ & $\begin{array}{l}\text { - (срочность выполнения } \\
\text { определяется самой } \\
\text { компанией) }\end{array}$ \\
\hline $\begin{array}{l}\text { Органы } \\
\text { власти }\end{array}$ & $\begin{array}{l}\text { Соблюдение законодательства } \\
\text { во всех аспектах, налоговые } \\
\text { отчисления }\end{array}$ & $\begin{array}{l}\text { + (законодательно } \\
\text { утверждена) }\end{array}$ & $\begin{array}{l}\text { + (административные и иные } \\
\text { наказания в случае } \\
\text { невыполнения запросов) }\end{array}$ & $\begin{array}{l}\text { + (запросы } \\
\text { контролирующих органов } \\
\text { должны выполняться в } \\
\text { установленные сроки) }\end{array}$ \\
\hline $\begin{array}{l}\text { Обществен } \\
\text { ные } \\
\text { органи- } \\
\text { зации }\end{array}$ & $\begin{array}{l}\text { Соблюдения законодательства, } \\
\text { благотворительность, развитие } \\
\text { региона }\end{array}$ & $\begin{array}{l}\text { - (нет } \\
\text { законодательной } \\
\text { базы, обязывающей } \\
\text { компанию учитывать } \\
\text { интересы) }\end{array}$ & $\begin{array}{l}\text { + (есть законодательная база, } \\
\text { а также вопросы имиджа, } \\
\text { освещения деятельности в } \\
\text { СМИ и др.) }\end{array}$ & $\begin{array}{l}\text { - (срочность выполнения } \\
\text { определяется самой } \\
\text { компанией) }\end{array}$ \\
\hline $\begin{array}{l}\text { Постав- } \\
\text { щики }\end{array}$ & $\begin{array}{l}\text { Выполнение договорных } \\
\text { обязательств, долгосрочные } \\
\text { отношения }\end{array}$ & $\begin{array}{l}\text { + (основывается на } \\
\text { договорных условиях) }\end{array}$ & $\begin{array}{l}\text { + (в связи со спецификой } \\
\text { работы закупка отдельных } \\
\text { видов сырья и услуг } \\
\text { проводится у ограниченного } \\
\text { числа поставщиков, узость } \\
\text { предложения порождает } \\
\text { властные инструменты для } \\
\text { поставщиков) }\end{array}$ & $\begin{array}{l}\text { + (обусловлена } \\
\text { договорными условиями и } \\
\text { характером отношений) }\end{array}$ \\
\hline
\end{tabular}

На основании анализа можно определить следующие группы стейкхолдеров (табл. 3).

Таблица 3. Основные группы стейкхолдеров ПАО «НЛМК»

\begin{tabular}{|l|l|l|}
\hline Группа & Подгруппа & Стейкхолдер \\
\hline Латентная группа (1 качество из 3) & Бездействующие (власть) & Общественные организации \\
\hline & Контролирующие (легитимность) & Просроюзные организации, Жители регионов \\
\hline Ожидающая группа (2 качества из 3) & $\begin{array}{l}\text { Пребующие (срочность) } \\
\text { легитимность) }\end{array}$ & - \\
\hline Категорическая группа (3 качества из 3) & $\begin{array}{l}\text { Зависимые (легитимность, } \\
\text { срочность) }\end{array}$ & Сотрудники компании, Потребители \\
\hline & Опасные (власть, срочность) & $\begin{array}{l}\text { Акционеры и инвесторы, Органы власти, } \\
\text { Поставщики }\end{array}$ \\
\hline
\end{tabular}


анализ | прогноз | управление

электронный научно-экономический журнал

Таблица 4. Ранжирование стейкхолдеров ПАО «НЛМК» на основе использования модели Брайсона

\begin{tabular}{|c|c|c|}
\hline Стейкхолдер & Характеристика интересов & Удовлетворенность \\
\hline $\begin{array}{l}\text { Сотрудники } \\
\text { компании }\end{array}$ & $\begin{array}{l}\text { Заинтересованы в заработной плате и социальном пакете (имеют право } \\
\text { требовать з/п и взыскивать ее в судебном порядке), безопасности труда } \\
\text { (законодательно регулируемая сфера, работодатель обязан обеспечивать } \\
\text { безопасность рабочих мест, условий труда и пр.), карьере }\end{array}$ & Средняя \\
\hline $\begin{array}{l}\text { Профсоюзные } \\
\text { организации }\end{array}$ & $\begin{array}{l}\text { Заинтересованы в соблюдении трудового законодательства и выполнении } \\
\text { условий трудового договора, достойном уровне заработной платы и } \\
\text { социальной защищенности сотрудников }\end{array}$ & Средняя \\
\hline Акционеры и инвесторы & $\begin{array}{l}\text { Дивидендные выплаты, высокие производственные и финансовые } \\
\text { результаты, соблюдение стратегии и достижение стратегических целей } \\
\text { компании }\end{array}$ & Средняя \\
\hline Потребители & $\begin{array}{l}\text { Высокое качество продукции, доступные цены, выполнение договорных } \\
\text { обязательств, своевременное рассмотрение претензий (обеспечено } \\
\text { договорными условиями) }\end{array}$ & Высокая \\
\hline Жители регионов & $\begin{array}{l}\text { Развитие региона, соблюдение экологических норм и ненанесение вреда } \\
\text { здоровью региона («грязный» характер производства НЛМК), } \\
\text { потенциальные рабочие места }\end{array}$ & Высокая \\
\hline Органы власти & Соблюдение законодательства во всех аспектах, налоговые отчисления & Средняя \\
\hline Общественные организации & Соблюдение законодательства, благотворительность, развитие региона & Высокая \\
\hline Поставщики & Выполнение договорных обязательств, долгосрочные отношения & Высокая \\
\hline
\end{tabular}

Таким образом, только путем анализа и внесения дополнительных разделов и, прежде всего, проработанного экономико-математического инструментария по взаимодействию компании со всеми заинтересованными сторонами, в ежегодную нефинансовую отчетность ПАО «НЛМК» можно снизить нефинансовые риски и поднять социальную ответственность бизнеса в целом.

Список использованной литературы:

1. Бариленко В.И. Информационно-аналитическое обеспечение устойчивого развития экономических субъектов: монография / под ред. проф. О.В. Ефимовой; В.И. Бариленко, О.В. Ефимова, Е.В. Никифорова и др.. - М.: Издательство «Русайнс», 2015. 160 с.

2. Басова М.М. Анализ социальных аспектов охраны труда и промышленной безопасности в условиях устойчивого развития компании // Современные проблемы управления природными ресурсами и развитием социально-экономических систем: материалы XII международной научной конференции; в 4-х ч. / под ред. А.В. Семенова, Н.Г. Малышева, Ю.С. Руденко. - М.: изд. ЧОУВО «МУ им. С.Ю. Витте», 2016. Ч. $2.716 \mathrm{c}$.

3. Ермакова М.Н. Практика взаимодействия с заинтересованными сторонами - путь инновационного развития компании // Научно-практический и теоретический журнал "Инновационное развитие экономики". - 2014. - № 4 (21). - С. 47-50.

4. Ефимова О.В. Отчет об устойчивом развитии как новая форма корпоративной отчетности компании // Аудиторские ведомости. 2014. № 8. С. 36-47

5. Официальный сайт ПАО «НЛМК»// [Электронный ресурс]. — Режим доступа: http://nlmk.com/

УДК 338 